\title{
Public interest in Cannabis during election season: a Google Trends analysis
}

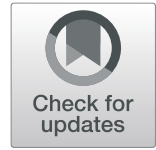

Trevor Torgerson º, Will Roberts, Drew Lester, Jam Khojasteh and Matt Vassar

\begin{abstract}
Introduction: Given that $72 \%$ of internet users seek out health information using an internet search engine (Google being the most popular); we sought to investigate the public internet search interest in cannabis as a health topic when cannabis legislation appeared on state ballots and during presidential elections.
\end{abstract}

Materials and methods: We searched Google Trends for "cannabis" as a health topic. Google Trends data were extracted during the time period of May 1, 2008 to May 1, 2019 for the United States (US) and select states (18) within the US including: Alaska, Arizona, Arkansas, California, Colorado, Florida, Maine, Massachusetts, Michigan, Missouri, Nevada, North Dakota, Ohio, Oregon, Oklahoma, South Dakota, Utah, and Washington when cannabis was on the ballot. These state elections were referenda, not legislative votes. We then compared the internet search interest for cannabis before and after each election. To evaluate whether any associations with changes in the volume of cannabis internet searches were specific to the cannabis topic, or also occurred with other topics of general interest during an election year, the authors ran additional analyses of previously popular debated policies during Presidential Elections that may act as control topics. These policies included Education, Gun Control, Climate Change, Global Warming, and Abortion. We used the autoregressive integrated moving average (ARIMA) algorithm to forecast expected relative internet search interests for the 2012 and 2016 Presidential Elections. Individual variables were compared using a linear regression analysis for the beta coefficients performed in Stata Version 15.1 (StataCorp).

Results: Public internet search interest for "cannabis" increased during the voting month above the previous mean internet search interest for all 18 bills. For the US, observed internet search interest during each Presidential Election was 26.9\% [95\% Cl, 18.4-35.4\%] greater than expected in 2012 and $29.8 \%$ [95\% Cl, 20.8-38.8\%] greater than expected in 2016. In 2016, significant state-level findings included an increase in relative internet search rates for cannabis in states with higher usage rates of cannabis in the past month (Coeff $(95 \% \mathrm{Cl}), 3.4(2.8-4.0))$ and past month illicit drug use except cannabis rates (Coeff (95\% Cl), 17.4 (9.8-25.0)). Relative internet search rates for cannabis from 2008 to 2019 were also associated with increased cannabis usage in the past month (Coeff (95\% Cl), 3.1 (2.5-3.7)). States with higher access to legal cannabis were associated with higher relative internet search volumes for cannabis (Coeff $(95 \% \mathrm{Cl}), 0.31(0.15-0.46))$. Of the five additional policies that were searched as topics, only two showed an increase in internet search interest during each Presidential Election. Climate Change increased by 3.5\% [95\% Cl, - 13-20\%] in 2012 and 20.1\% [95\% Cl, 0-40\%] in 2016 while Global Warming increased by 1.1\% [95\% Cl, - 19-21\%] in 2012 and 4.6\% [95\% Cl, - 6-15\%] in 2016.

(Continued on next page)

* Correspondence: trevor.torgerson@okstate.edu

Office of Medical Student Research, Oklahoma State University Center for Health Sciences, 1111 West 17th Street, Tulsa, OK 74107, USA

(c) The Author(s). 2020 Open Access This article is licensed under a Creative Commons Attribution 4.0 International License, which permits use, sharing, adaptation, distribution and reproduction in any medium or format, as long as you give appropriate credit to the original author(s) and the source, provide a link to the Creative Commons licence, and indicate if changes were made. The images or other third party material in this article are included in the article's Creative Commons licence, unless indicated otherwise in a credit line to the material. If material is not included in the article's Creative Commons licence and your intended use is not permitted by statutory regulation or exceeds the permitted use, you will need to obtain permission directly from the copyright holder. To view a copy of this licence, visit http://creativecommons.org/licenses/by/4.0/. 


\begin{abstract}
(Continued from previous page)
Conclusion: Based on these results, we expect public interest in cannabis will spike prior to the Presidential election in 2020. Of the five selected control policies, only two showed an increase in internet search interest during both Presidential Elections and neither exceeded the internet search increase of cannabis. These results may indicate the growing awareness of cannabis in the US and mark a possible target for the timely dissemination of evidence-based information regarding cannabis and its usage/side-effects during future elections. Consequently, the results of this study may be important to physicians since they will likely receive an increased volume of questions relating to cannabis and its therapeutic uses during election season from interested patients. We recommend establishing a cannabis repository of evidence-based information, providing physician education, and a dosing guide be created to enable physicians to provide high quality care around the issue of cannabis.
\end{abstract}

Keywords: Cannabis, Medical marijuana, Google trends, Elections, Politics, Internet search

\section{Introduction}

In 2016, 22.2 million Americans over the age of 12 reported having used cannabis in the last 30 days (National Academies of Sciences, Engineering 2017). Cannabis continues to spark political debate regarding legalization for medicinal and recreational purposes (National Institute on Drug Abuse 2019). The potential economic and public health ramifications make legalization a polarizing issue. Healthcare, mental health, and addiction have been highly influential topics among presidential debates, of which, cannabis is only increasing in public awareness. Within healthcare specifically, cannabis has been discussed as an alternative therapeutic option to reducing the prevalence of opioid prescription use, including the abuse of these drugs (Wen and Hockenberry 2018; The October democratic debate transcript 2019).

The majority of ballot measures regarding adult use of recreational and medicinal cannabis have been included in the same voting cycle as presidential and midterm elections; however, the effect these elections have on public awareness of cannabis as a health topic is not yet known. Given that $72 \%$ of internet users seek out health information using an internet search engine (Fox and Duggan 2013); we sought to investigate the public internet search interest in cannabis as a health topic when cannabis legislation appeared on state ballots and during the presidential elections. We also aim to examine if states with higher increases in relative internet search rates for cannabis were associated with greater cannabis and illicit drug use the month before the 2016 election. Finally, we investigate state-level associations between relative internet search rates for cannabis and cannabis use statistics from the National Survey on Drug Use and Health.

\section{Materials and methods}

On June 26, 2019, one author, (TT) searched Google Trends (https://trends.google.com/trends/?geo=US) for "cannabis" as a health topic and the relative-search volume (RSV), which is a query share for a particular time series, was then measured (Nuti et al. 2014). Through Google Trends' search algorithm, search words can be defined as terms or topics depending on specific search needs. Search terms show matches for all terms in the query in the language given, while topics are a group of terms that share the same concept in any language. For example, when searching the term "banana," results include terms like "banana", "banana sandwich", or "Banana Republic". However, if the topic "London," is searched results include terms categorized under the said topic such as "Capital of the UK" and "Londres," which is "London" in Spanish (Compare trends search terms - trends help 2020). Therefore, searching for cannabis as a topic would allow the authors to encompass search words that fall under the cannabis category such as marijuana, medical marijuana, and recreational cannabis. Thenceforth, the Google Trends application allowed the authors to produce a series of time-trends graphs quantifying cannabis-specific online activity during the time of the election. This method is similar to previous studies looking at drug-legislative changes (Bright et al. 2013; Forsyth 2012). To evaluate whether changes in the volume of cannabis internet searches were specific to cannabis alone, or if these changes occurred with other topics of general interest during an election year, the authors ran additional analyses of previously popular debated issues during Presidential Elections that may act as control topics. These issues included Education, Gun Control, Climate Change, Global Warming, and Abortion. Prior to beginning the author's internet search, the computer's cache, cookies, and data were cleared on the Google Chrome browser to ensure that previous internet searches would not influence their results. "Cannabis", and the additional control topics, were extracted from Google Trends data during the time period of May 1, 2008 to May 1, 2019 for the United States (US). Then, using the same date range, relative internet search data for "cannabis" was extracted for selected states (18) 
within the US including: Alaska, Arizona, Arkansas, California, Colorado, Florida, Maine, Massachusetts, Michigan, Missouri, Nevada, North Dakota, Ohio, Oregon, Oklahoma, South Dakota, Utah, and Washington when cannabis was on the ballot (Marijuana on the ballot - Ballotpedia 2019). These state elections were referenda, not legislative votes.

For each state election, the mean internet search interest for "cannabis" was obtained from May 1, 2008 through the month before each specific state election. This mean internet search interest was then compared to the internet search interest for "cannabis" during the state election month and cannabis use characteristics for the prior year. For example, the election date in Alaska occurred in November 2014, therefore we compared the mean internet search interest from May 1, 2008 to October 31, 2014 with the mean internet search interest during November, 2014. Only bills relating directly to the legalization of medicinal or recreational cannabis were included. When two bills were voted on for the same state within the set time period, the most recent ballot was used for analysis. Google Trends data is displayed as a relative search volume. The search volume for a given month over a prespecified time period (May 12,008 to October 31, 2014 in our example above) is given a relative search volume for each month ranging from 0 to 100. The relative search volume number for each month represents the search interest for a topic (cannabis in this study) relative to the month with the highest number of searches for the topic within the given time period. The relative search volume of 100 represents the upper limit and is the topic's highest moment of popularity during that search period. All other monthly relative search volumes within the timeframe are displayed relative to the upper limit. For example, a relative search volume of 50 means there were half as many searches that month, compared to the highest number of searches within the timeframe.

Additionally, authors extracted state specific internet search rates for cannabis. To obtain the relative internet search rates for each state Google takes the total internet searches for a specific phrase originating from each state and divides it by the total number of Google searches from that state over the prespecified time frame. Similar to above, this relative internet search rate is then scaled from 0 and 100 relative to the state with the highest percentage of google searches for the topic within the given timeframe. This scaled search volume is referred to as relative search rate. Relative search rates for cannabis were obtained for each state in two separate time periods, May 1, 2008 to May 1, 2019 and the year of 2016. Each time period was used for specific analyses as outlined below.
In 2018, Americans for Safe Access evaluated each state's medical cannabis laws in what they called "A Patient-Focused Analysis of the Patchwork of State Laws" (Reports [Internet] 2020). Americans for Safe Access graded state's on their state-level access to legal cannabis. This access to legal cannabis score was based on factors from 5 categories: patient rights and civil protections, access to medicine, ease of navigation, functionality and consumer safety, and provider requirements (Reports [Internet] 2020). Each category is worth 100 points based on many specific qualifications. States' grades were then calculated as a percentage of the 500 possible points. States without any form of medical cannabis laws at the time were not awarded grades (Idaho, Kansas, Nebraska, and South Dakota). Excluding the states without cannabis laws, we used specific relative search rates from the remaining 46 states and compared them with statistics from the National Survey on Drug Use and Health for 2016-17 for persons over the age of 18 years old (Comparison of 2015-2016 and 2016-2017 NSDUH population percentages 2020). State specific cannabis internet searches from 2016 were compared with cannabis use in the past month (18+ years old), illicit drug use in the past month excluding cannabis use (18+ years old) and access to legal cannabis grade. Each association was based on 46 pairs of data. State specific internet searches for cannabis from 2008 to 2019 were compared with "any illicit drug use in the past month (18+ years old)". Comparatively, each control variable (Education, Gun Control, Climate Change, Global Warming, and Abortion) was also evaluated alongside "cannabis use in the past month (18+ years old)" and illicit drug use excluding cannabis in the past month (18+ years old) from the National Survey on Drug Use and Health for 2016-17 using the same methods outlined above. Individual variables were compared using a linear regression analysis for the beta coefficients performed in Stata Version 15.1 (StataCorp).

An autoregressive integrated moving average (ARIMA) algorithm was used to forecast expected relative internet search volumes for the 2012 and 2016 Presidential Elections. Data from Google Trends for the entire United States from May 1, 2008 to May 1, 2019 was extracted and used for this model The ARIMA model is based on time series analysis and prediction through a combination of seasonal variables. To start, all data was converted into a time series according to the year and month format, and was divided into two parts: preelection and post-election for both 2012 and 2016. The pre-election data was used as model data and the postelection data was used as comparison data. Finally, the ARIMA model provides a predictive forecast for internet search queries had the elections not occurred (Liu et al. 2018; Liu et al. 2016). Additionally, in the event an 
increase in relative internet search volume occurred during the Presidential Elections of 2012 and 2016 we compared the mean internet search volume 6 months before each election and the mean internet search volume 6 months after each election to determine if the increase was momentary or sustained. $\mathrm{R}$ version 3.2.1 (R Foundation) was used for the ARIMA model and Stata Version 15.1 (StataCorp) was used for all statistical analyses.

\section{Results}

Eighteen states and 18 total bills were included for analysis. Public internet search interest for cannabis increased for all 18 bills during the election month compared to rates preceding the election month. Across all 18 bills, the mean percent increase for internet search interest during the voting month was $48.1 \%$ [95\% CI, 40.4-55.7\%]. A complete depiction of results is outlined in Table 1.

For the US, observed internet search interest during each Presidential Election was 26.9\% [95\% CI, 18-35\%] greater than expected in 2012 and 29.8\% [95\% CI, 2139\%] greater than expected in 2016 (Fig. 1). The mean relative internet search volume 6 months before the 2012 Presidential Election was 55.8 [95\% CI, 54.4-57.2], the relative internet search volume during election month was 82 , and the mean relative internet search volume 6 months after the election was 62.3 [95\% CI, 57.7-
67.0]. The mean relative internet search volume 6 months before the 2016 Presidential Election was 69.7 [95\% CI, 68.6-70.8], the relative internet search volume during election month was 100 , and the mean relative internet search volume 6 months after the election was 76.3 [95\% CI, 72.8-79.8]. Of the five additional issues that were searched as topics, only two showed an increase in internet search interest during each Presidential Election. Climate Change increased by 3.5\% [95\% CI, - 13-20\%] in 2012 and 20.1\% [95\% CI, 0-40\%] in 2016 while Global Warming increased by $1.1 \%$ [95\% CI, - 1921\%] in 2012 and 4.6\% [95\% CI, -6-15\%] in 2016. Table 2 presents the results of all additionally searched issues during the Presidential Elections.

In 2016, significant state-level findings (Fig. 2) included an increase in relative internet search rates for cannabis in states with higher usage rates of cannabis in the past month (Coeff (95\% CI), 3.4 (2.8-4.0)). Relative internet search rates for cannabis from 2008 to 2019 were also associated with increased cannabis usage in the past month (Coeff (95\% CI), 3.1 (2.5-3.7)). States with higher access to legal cannabis grades were associated with higher relative search volumes for cannabis (Coeff (95\% CI), $0.31(0.15-0.46))$. Similar to cannabis, relative internet searches for "climate control" and "global warming" were associated with significant associations between "cannabis use in the past month", "drug

Table 1 Public internet search interest in Cannabis legalization when Cannabis is on the Ballot

\begin{tabular}{lllll}
\hline State & Election date & Medical or recreational & Pre-election internet search interest ${ }^{\text {a }}$ [95, Cl] & Increase ${ }^{\mathbf{b}}$ [95, Cl] \\
\hline Alaska & Nov 2014 & Recreational & $36.2[34.5-37.9]$ & $63.8 \%[62.1-65.5]$ \\
Arizona & Nov 2016 & Recreational & $56.5[53.9-59.1]$ & $43.5 \%[40.9-46.1]$ \\
Arkansas & Nov 2016 & Medical & $43.0[41.3-44.7]$ & $57.0 \%[55.3-58.7]$ \\
California & Nov 2016 & Recreational & $45.3[43.3-47.2]$ & $52.7 \%[50.8-54.7]$ \\
Colorado & Nov 2012 & Recreational & $35.6[33.4-37.8]$ & $29.4 \%[27.2-31.6]$ \\
Florida & Nov 2016 & Medical & $51.4[49.7-53.1]$ & $48.6 \%[46.9-50.3]$ \\
Maine & Nov 2016 & Recreational & $39.2[37.8-40.7]$ & $60.8 \%[59.3-62.2]$ \\
Massachusetts & Nov 2012 & Medical & $39.7[38.1-41.3]$ & $30.3 \%[28.7-31.9]$ \\
Michigan & Nov 2018 & Recreational & $39.6[38.5-40.8]$ & $60.4 \%[59.2-61.5]$ \\
Missouri & Nov 2018 & Medical & $40.7[39.3-42.1]$ & $59.3 \%[57.9-60.7]$ \\
Nevada & Nov 2016 & Recreational & $28.4[27.2-29.6]$ & $44.6 \%[43.4-45.8]$ \\
North Dakota & Nov 2016 & Medical & $35.5[33.9-37.1]$ & $64.5 \%[62.9-66.1]$ \\
Ohio & Nov 2015 & Recreational & $60.4[58.5-62.3]$ & $28.6 \%[26.7-30.5]$ \\
Oklahoma & June 2018 & Medical & $26.8[25.5-28.1]$ & $64.2 \%[62.9-65.5]$ \\
Oregon & Nov 2014 & Recreational & $34.9[33.4-36.3]$ & $11.1 \%[9.7-12.6]$ \\
South Dakota & Nov 2010 & Medical & $57.4[52.4-62.4]$ & $36.6 \%[31.6-41.6]$ \\
Utah & Nov 2018 & Medical & $48.9[46.4-51.4]$ & $41.6[39.6-43.6]$ \\
Washington & Nov 2012 & Recreational & $51.1 \%[48.6-53.6]$ \\
\hline
\end{tabular}

${ }^{a}$ For each state election, the mean internet search interest for "cannabis" was obtained from May 1, 2008 through the month before each specific state election ${ }^{\mathrm{b}}$ The percent increase in relative internet search interest during the voting month compared to the mean relative internet search interest beginning May 1 , 2008 and ending the month prior to voting on the bill 


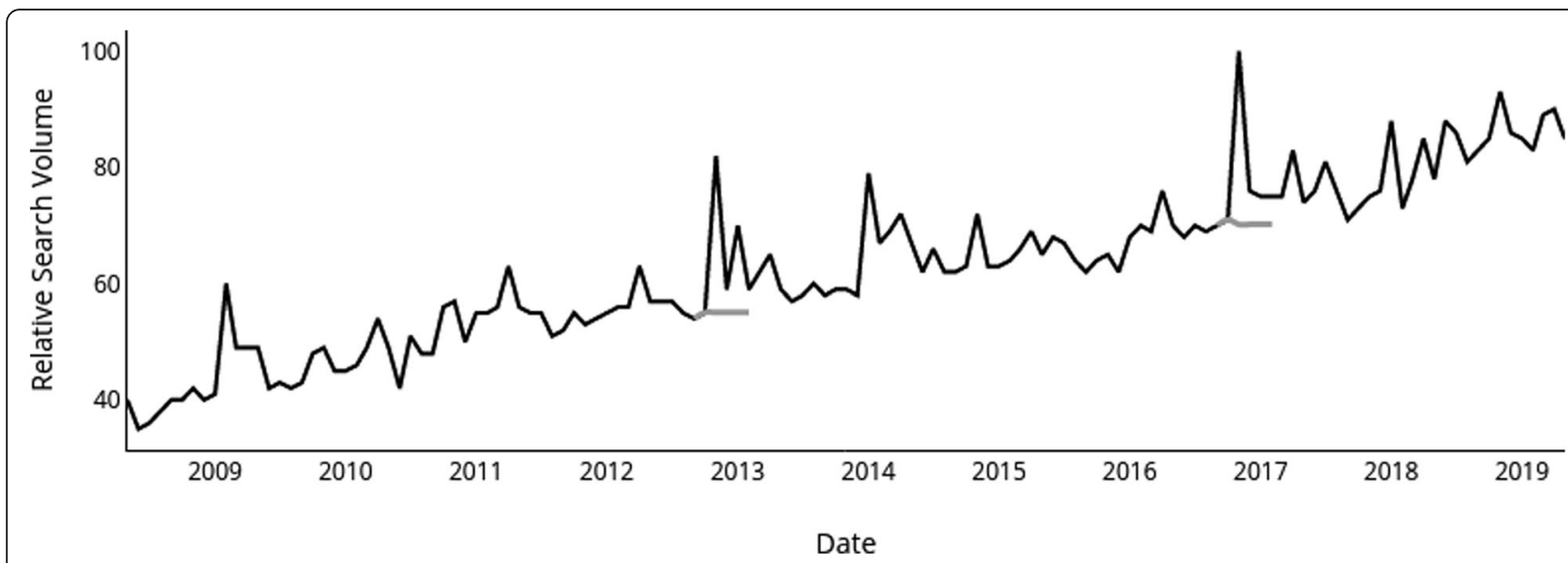

Fig. 1 Relative internet search interest in "Cannabis" as a health topic between 2008 and 2019. Legend: Monthly trends in relative internet search volume for "Cannabis" as a health topic in the United States from 2008 to 20,019 was measured using Google Trends. Observed internet search trends (black line) vs. expected forecasts (gray line) calculated using an ARIMA model following the presidential elections of 2012 and 2016. The spike in searches for cannabis during January of 2014 is most likely due to the start of the first legal recreational cannabis sales in Colorado

use in the past month excluding cannabis", and access to legal cannabis grade (Table 3 ).

\section{Discussion}

This study showed that US relative internet search interest in cannabis as a health topic increased dramatically during election months when cannabis legislation was

Table 2 Public internet search interest in major public issues during the 2012 and 2016 presidential elections

\begin{tabular}{ll}
\hline Education & Increase [95\%, Cl] \\
\hline November 2012 & $-4.0 \%(-11-3)$ \\
November 2016 & $2.0 \%(-3-7)$ \\
Gun control & \\
November 2012 & $5.6 \%(0-11)$ \\
November 2016 & $-0.8 \%(-25-14)$ \\
Climate change & \\
November 2012 & $3.5 \%(-13-20)$ \\
November 2016 & $20.1 \%(0-40)$ \\
Global warming & \\
November 2012 & $1.1 \%(-19-21)$ \\
November 2016 & $4.6 \%(-6-15)$ \\
Abortion & \\
November 2012 & $-2.0 \%(-11-7)$ \\
November 2016 & $2.2 \%(-6-11)$ \\
Cannabis & \\
November 2012 & $26.9(18-35)$ \\
November 2016 & $29.8(21-39)$ \\
\hline
\end{tabular}

Google Trends provided relative internet search volume data for the election month and the mean internet search volume for the election month was compared against the forecasted autoregressive integrated moving average (ARIMA). The ARIMA model provides a forecast or predicted relative internet search volume in the event the election did not occur on state ballots. Of the 18 total states analyzed, the mean percent increase for relative search volume during the voting month was $48.3 \%$. In addition, this search volume also increased during the 2012 and 2016 Presidential Election months by 26.9 and $29.8 \%$, respectively. Of the five selected control policies, only two showed an increase in internet search volume during both Presidential Elections and neither exceeded the internet search increase of cannabis. These results may indicate the growing awareness of cannabis in the US and mark a possible target for the timely dissemination of evidencebased information regarding cannabis and its usage/sideeffects during future elections. In addition, this study's analysis highlighted significant state-level associations with cannabis internet search rate increases. For example, states with higher increases in relative internet search rates for cannabis were associated with a higher incidence of cannabis and past month illicit drug use except cannabis during the year of 2016. Furthermore, increases in relative internet search rates for cannabis from 2008 to 2019 were also associated with increased cannabis usage in the past month and higher access to legal cannabis grades. Thus, policymakers and state legislators may use this information to target high-risk states during election periods and possibly prevent adverse events that are related to excessive cannabis and illicit drug use through marketing and educational tactics through the dissemination of evidence-based resources. Additionally, we underscore that results from these analyses are correlational rather than causal and should be interpreted as such.

A study conducted by Linkov et al. (2010) in 2010, investigated public interest in disasters using Google Trends to determine when people are most interested in such global events. This study retrospectively 


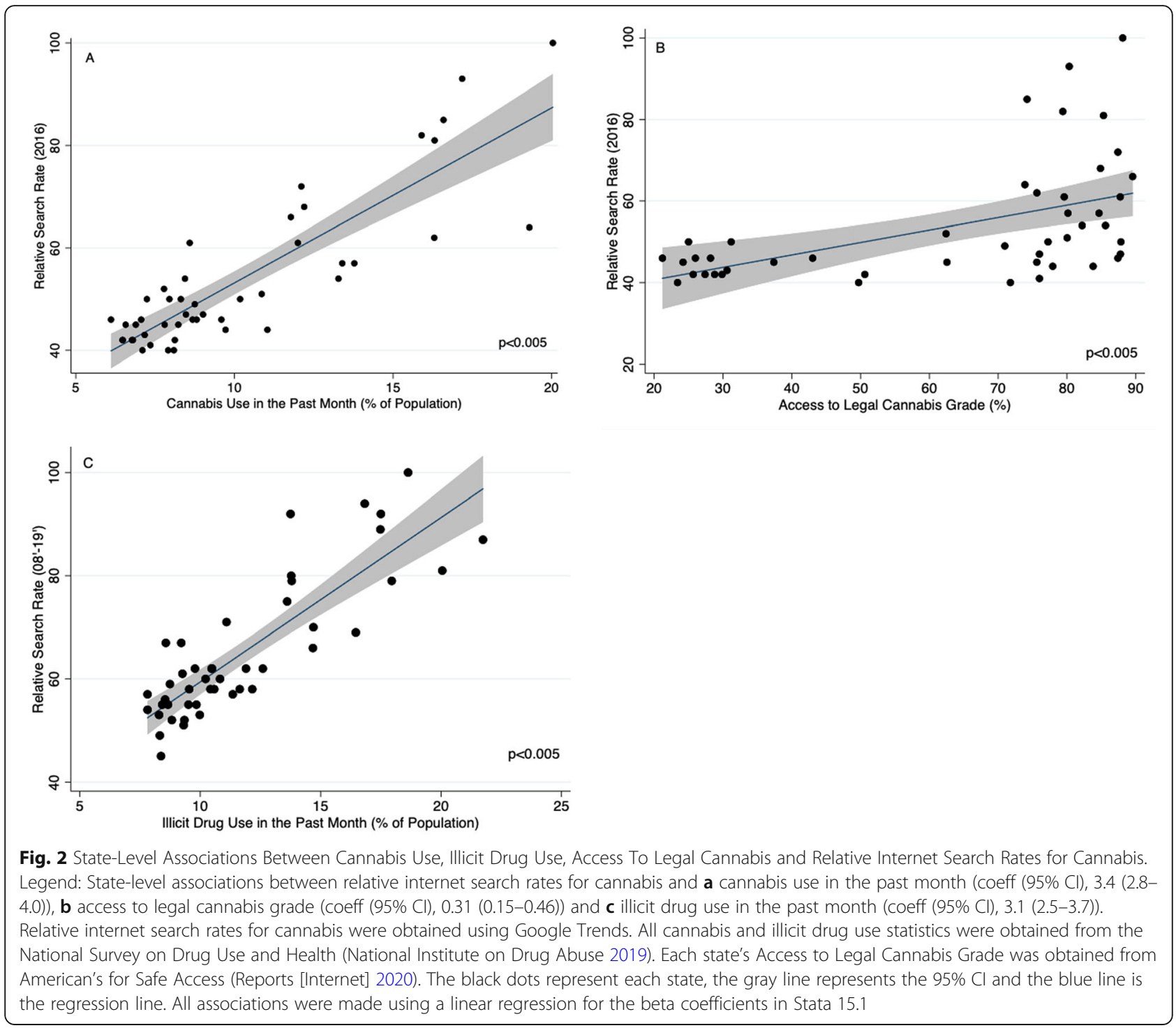

examined four events that may have had a major effect on public interest by searching for the terms "tsunami", "hurricane", "H1N1", and "earthquake" during a 6 year time period from 2004 to 2010 and then examined the associated Google Trends interest curves. The results of this study showed that despite differing levels of interest, all four events showed an identical interest curve increasing after the event and decreasing shortly after the spike. The authors concluded that since the interest level curve increases shortly after the events, information must be disseminated quickly in the associated time-frame to allow for proper education regarding the searched topic. Our results show a similar curve to the disasters searched where there is an abrupt increase in the interest level and a sharp decay shortly after. Furthermore, this information provides additional evidence of an opportune time for the dissemination of evidencebased information regarding cannabis during elections.

Based on these results, we can expect public interest in cannabis to spike again prior to the Presidential Election in 2020 and future elections. With this expected spike in interest, there is an imperative need for accurate and evidenced-based information regarding cannabis to be available to the public during these periods of increased public interest. Consequently, the implications of this study are important to physicians since they will likely receive an increased volume of questions relating to cannabis and its therapeutic uses during election season from interested patients. However, one study found that half of the primary care physicians surveyed were not ready or did not want to answer questions regarding cannabis (Philpot et al. 
Table 3 Association between topic-specific internet search rates and state-level drug use characteristics

\begin{tabular}{|c|c|c|c|c|}
\hline Internet search term & State-level drug use characteristic & Coefficient ( $p$ value) & $95 \% \mathrm{Cl}$ & $\mathrm{R}^{\wedge} 2$ \\
\hline \multirow[t]{3}{*}{ Education } & cannabis use in the past month ( $18+$ years old) & $-0.12(0.77)$ & $-1.0-0.74$ & 0.00 \\
\hline & drug use in the past month (excluding cannabis use) $(18+$ years old) & $1.1(0.73)$ & $-5.6-7.8$ & 0.00 \\
\hline & access to legal cannabis & $-0.06(0.37)$ & $-0.19-0.07$ & 0.02 \\
\hline \multirow[t]{3}{*}{ Gun control } & cannabis use in the past month $(18+$ years old $)$ & $1.2(0.01)$ & $0.31-2.1$ & 0.14 \\
\hline & drug use in the past month (excluding cannabis use) $(18+$ years old) & $4.0(0.28)$ & $-3.4-11.3$ & 0.03 \\
\hline & access to legal cannabis & $0.01(0.91)$ & $-0.14-0.15$ & 0.00 \\
\hline \multirow[t]{3}{*}{ Climate change } & cannabis use in the past month ( $18+$ years old $)$ & $3.2(<0.005)$ & $2.5-4.0$ & 0.60 \\
\hline & drug use in the past month (excluding cannabis use) $(18+$ years old) & $14.8(<0.005)$ & $6.1-23.5$ & 0.20 \\
\hline & access to legal cannabis & $0.27(<0.005)$ & $0.09-0.44$ & 0.18 \\
\hline \multirow[t]{3}{*}{ Global warming } & cannabis use in the past month ( $18+$ years old) & $2.1(<0.005)$ & $1.3-2.9$ & 0.41 \\
\hline & drug use in the past month (excluding cannabis use) (18+ years old) & $10.0(0.006)$ & $3.0-17.0$ & 0.15 \\
\hline & access to legal cannabis & $0.17(0.02)$ & $0.03-0.31$ & 0.12 \\
\hline \multirow[t]{3}{*}{ Abortion } & cannabis use in the past month ( $18+$ years old $)$ & $-0.88(0.006)$ & $-1.5--0.26$ & 0.15 \\
\hline & drug use in the past month (excluding cannabis use) (18+ years old) & $-2.44(0.34)$ & $-7.6-2.7$ & 0.02 \\
\hline & access to legal cannabis & $-0.09(0.7)$ & $-0.19-0.01$ & 0.07 \\
\hline \multirow[t]{3}{*}{ Cannabis } & cannabis use in the past month ( $18+$ years old) & $3.4(<0.005)$ & $2.8-4.0$ & 0.74 \\
\hline & drug use in the past month (excluding cannabis use) $(18+$ years old) & $17.4(<0.005)$ & $9.8-25.0$ & 0.33 \\
\hline & access to legal cannabis & $0.31(<0.005)$ & $0.15-0.46$ & 0.26 \\
\hline
\end{tabular}

Internet search rates were obtained using Google Trends for 2016 and these rates were observed for associations to the National Survey on Drug Use and Health for 2016-17 statistics (National Institute on Drug Abuse 2019) and access to legal cannabis grades using a linear regression for the beta coefficient values in Stata 15.1. State-Level Drug Use Characteristics were from the National Survey on Drug Use and Health (National Institute on Drug Abuse 2019). Access to legal cannabis was based upon the American's for Safe Access state cannabis grade (Reports [Internet] 2020)

2019). Given the likely increase in cannabis internet search interest in 2020 and the controversy that surrounds cannabis, physician awareness and education is paramount for providing evidence-based recommendations to these patients.

To facilitate awareness, we detail a few recommendations the medical community may consider to enable physicians to provide the highest quality care. First, we recommend a cannabis repository of evidence-based information be established for physicians and widely promoted. This repository should be easily searchable and free of stakeholder bias to inform provider and patient medical decisions. Second, we recommend educating physicians on the inherent conflicts of interest within cannabis legislation and the difficulties in conducting clinical trials to provide evidence for its effectiveness (Hill 2019; Bowling and Glantz 2019). Lastly, given that many resident and fellow physicians report having little knowledge about medicinal cannabis, we suggest that efforts be made to educate and train future physicians on the risks and benefits of cannabis (Evanoff et al. 2017). One avenue to this education could be implementing cannabis education into the curriculum of medical schools and post-graduate residency programs. We feel these actions will better prepare physicians to provide evidence-based guidance to their patients on issues relating to medicinal cannabis despite little evidence amongst the literature.

Regarding the strengths of our study, we used previously published methodology for measuring public interest in a specific topic as well as forecasting ARIMA models (Ayers et al. 2017; Ayers et al. 2019; Torgerson et al. 2019). We also used data from a validated, largescale, nationally representative survey (NSDUH) to make associations with cannabis search volume. However, we are aware that while Google is the most commonly used internet search engine it may not be a complete representation of public internet activity in its entirety. We also must note that the state-level associations are correlations and not causative and hence may be subject to unforeseen confounding.

\section{Conclusion}

In summary, our investigation showed that US relative internet search interest in cannabis increased dramatically when cannabis legislation was on state ballots during election months. Based on these results, we expect public interest in cannabis will spike prior to the Presidential election in 2020 which could provide an opportune time for the dissemination of evidence-based information through online platforms. Consequently, the physician 
implications are important considering the likely increase in volume of questions relating to cannabis and its therapeutic uses during election season. We recommend establishing a cannabis repository of evidencebased information, providing physician education, and a dosing guide be created to enable physicians to provide high quality care around the issue of cannabis.

\section{Abbreviation}

ARIMA: Autoregressive integrated moving average

\section{Acknowledgements}

None.

\section{Authors' contributions}

Data Collection: TT, DL; Data Analysis: TT, JK, DL, MV; Writing and Editing: TT, WR, MV, DL; Project Management: TT, MV. The author(s) read and approved the final manuscript.

\section{Funding}

None.

\section{Availability of data and materials}

Data is available upon request.

\section{Ethics approval and consent to participate}

This study does not meet the regulatory definition of human subjects research and, thus, excluded from IRB oversight.

\section{Consent for publication}

N/A

\section{Competing interests}

Dr. Matt Vassar reports receipt of funding from the National Institute on Drug Abuse, the National Institute on Alcohol Abuse and Alcoholism, the US Office of Research Integrity, Oklahoma Center for Advancement of Science and Technology, and internal grants from Oklahoma State University Center for Health Sciences - all outside of the present work. All other authors report no conflicts of interest.

Received: 4 February 2020 Accepted: 11 September 2020

Published online: 22 September 2020

\section{References}

Ayers JW, Althouse BM, Leas EC, Dredze M, Allem J-P. Internet searches for suicide following the release of 13 reasons why. JAMA Intern Med. 2017; 177(10):1527-9.

Ayers JW, Nobles AL, Dredze M. Media trends for the substance abuse and mental health services administration 800-662-HELP addiction treatment referral services after a celebrity overdose [Internet]. JAMA Internal Med. 2019;179:441. https://doi.org/10.1001/jamainternmed.2018.6562.

Bowling CM, Glantz SA. Conflict of interest provisions in state laws governing medical and adult use Cannabis. Am J Public Health. 2019;109(3):423-6.

Bright SJ, Bishop B, Kane R, Marsh A, Barratt MJ. Kronic hysteria: exploring the intersection between Australian synthetic cannabis legislation, the media, and drug-related harm. Int I Drug Policy, 2013:24(3):231-7.

Compare trends search terms - trends help [Internet]. [cited 2020 Mar 27]. Available from: https://support.google.com/trends/answer/4359550?hl=en.

Comparison of 2015-2016 and 2016-2017 NSDUH population percentages (50 States and the District of Columbia) | CBHSQ data [Internet]. [cited 2020 Jan 7]. Available from: https://www.samhsa.gov/data/report/comparison-2015-2 016-and-2016-2017-nsduh-population-percentages-50-states-and-district.

Evanoff AB, Quan T, Dufault C, Awad M, Bierut LJ. Physicians-in-training are not prepared to prescribe medical marijuana. Drug Alcohol Depend. 2017;180: $151-5$

Forsyth AJM. Virtually a drug scare: mephedrone and the impact of the internet on drug news transmission. Int I Drug Policy. 2012:23(3):198-209.

Fox S, Duggan M. Health online 2013. Health. 2013;2013:1-55.
Hill KP. Medical use of Cannabis in 2019. JAMA. 2019. https://doi.org/10.1001/ jama.2019.11868.

Linkov F, Ardalan A, Hennon M, Shubnikov E, Serageldin I, Laporte R. Using Google trends to assess interest in disasters. Prehosp Disaster Med. 2010; 25(5):482-4.

Liu L, Luan RS, Yin F, Zhu XP, Lü Q. Predicting the incidence of hand, foot and mouth disease in Sichuan province, China using the ARIMA model. Epidemiol Infect. 2016;144(1):144-51.

Liu Y, Hu XM, Chen Y, Fu ZW. Application of ARIMA model in prediction of mortality rate of suicide in Hainan province. Zhonghua Liu Xing Bing Xue Za Zhi. 2018:39(5):664-8.

Marijuana on the ballot - Ballotpedia [Internet]. Ballotpedia. [cited 2019 Jun 27]. Available from: https://ballotpedia.org/Marijuana_on_the_ballot.

National Academies of Sciences, Engineering, and Medicine, Health and Medicine Division, Board on Population Health and Public Health Practice, Committee on the Health Effects of Marijuana: An Evidence Review and Research Agenda. Cannabis: Prevalence of Use, Regulation, and Current Policy Landscape. National Academies Press (US); 2017.

National Institute on Drug Abuse. Nationwide trends [Internet]. [cited 2019 Jun 27]. Available from: https://www.drugabuse.gov/publications/drugfacts/ nationwide-trends.

Nuti SV, Wayda B, Ranasinghe I, Wang S, Dreyer RP, Chen SI, et al. The use of google trends in health care research: a systematic review. PLoS One. 2014; 9(10):e109583.

Philpot LM, Ebbert JO, Hurt RT. A survey of the attitudes, beliefs and knowledge about medical cannabis among primary care providers. BMC Fam Pract. 2019;20(1):17.

Reports [Internet]. Americans for safe access. [cited 2020 Jan 7]. Available from: https://www.safeaccessnow.org/asa_reports.

The October democratic debate transcript. The Washington Post [Internet]. 2019 [cited 2019 Oct 23]; Available from: https://www.washingtonpost.com/ politics/2019/10/15/october-democratic-debate-transcript/.

Torgerson T, Khojasteh J, Vassar M. Public awareness for a sexual assault hotline following a grey's anatomy episode. JAMA Intern Med. 2019. https://doi.org/ 10.1001/jamainternmed.2019.5280.

Wen $\mathrm{H}$, Hockenberry JM. Association of medical and adult-use marijuana laws with opioid prescribing for medicaid enrollees. JAMA Intern Med. 2018; 178(5):673-9.

\section{Publisher's Note}

Springer Nature remains neutral with regard to jurisdictional claims in published maps and institutional affiliations.

Ready to submit your research? Choose BMC and benefit from:

- fast, convenient online submission

- thorough peer review by experienced researchers in your field

- rapid publication on acceptance

- support for research data, including large and complex data types

- gold Open Access which fosters wider collaboration and increased citations

- maximum visibility for your research: over $100 \mathrm{M}$ website views per year

At $\mathrm{BMC}$, research is always in progress.

Learn more biomedcentral.com/submission 